University of Nebraska - Lincoln DigitalCommons@University of Nebraska - Lincoln

US Army Research

U.S. Department of Defense

2012

\title{
A moderated mediation test of personality, coping, and health among deployed soldiers
}

Ann Chunyan Peng

Michigan State University, pengchu1@msu.edu

Laura T. Riolli

California State University - Sacramento

John Schaubroeck

Michigan State University

Everett S. P. Spain

United States Army

Follow this and additional works at: http://digitalcommons.unl.edu/usarmyresearch

Peng, Ann Chunyan; Riolli, Laura T.; Schaubroeck, John; and Spain, Everett S. P., "A moderated mediation test of personality, coping, and health among deployed soldiers" (2012). US Army Research. 274.

http://digitalcommons.unl.edu/usarmyresearch/274

This Article is brought to you for free and open access by the U.S. Department of Defense at DigitalCommons@University of Nebraska - Lincoln. It has been accepted for inclusion in US Army Research by an authorized administrator of DigitalCommons@University of Nebraska - Lincoln. 


\title{
A moderated mediation test of personality, coping, and health among deployed soldiers
}

\author{
ANN CHUNYAN PENG ${ }^{1 *}$, LAURA T. RIOLLI ${ }^{2}$, JOHN SCHAUBROECK ${ }^{1,3}$ AND \\ EVERETT S. P. SPAIN ${ }^{4}$ \\ ${ }^{1}$ Department of Management, Michigan State University, East Lansing, Michigan, U.S.A. \\ ${ }^{2}$ College of Business Administration, California State University-Sacramento, Sacramento, California, U.S.A. \\ ${ }^{3}$ Department of Psychology, Michigan State University, East Lansing, Michigan, U.S.A. \\ ${ }^{4}$ United States Army, U.S.A.
}

\begin{abstract}
Summary Our study examines how personality and coping influence soldiers' psychological health among 648 US Army personnel who were at that time deployed in Iraq at the height of an insurgency. Conscientiousness, neuroticism, and extraversion were associated with different coping behaviors, and these were in turn related to psychological distress. Conscientiousness was positively associated with problem-focused coping and negatively with avoidance coping, whereas neuroticism was most positively associated with avoidance coping. Extraversion was positively related to both seeking social support and avoidance coping. As expected, avoidance coping was positively associated with psychological distress. Coping style explained more variance in the relationship between personality and distress among soldiers who perceived higher levels of threat, thus supporting a moderated mediation hypothesis. We discuss implications for facilitating the stress coping of workers who face acute and potentially traumatic stress exposures. Copyright (C) 2011 John Wiley \& Sons, Ltd.
\end{abstract}

Keywords: personality; coping; combat stress; psychological distress

\section{Introduction}

Physically dangerous work, such as that of first responders and military personnel, is known to have adverse health consequences even for those who are not injured or killed (Jermier, Gaines, \& McIntosh, 1989). These symptoms may arise not only from the threatening conditions these workers face regularly but also from witnessing very distressing events. Soldiers at war are a dramatic case in point. The wars in Afghanistan and in Iraq have produced a new generation of veterans who are at potential risk for chronic mental health problems (Litz, 2007). A comprehensive investigation of soldiers deployed to Afghanistan and Iraq showed that 19 per cent of veterans returning from Iraq reported having mental health problems (Hoge, Auchterlonie, \& Milliken, 2006), and 13 per cent of the soldiers deployed to Iraq met the screening criteria for post-traumatic stress disorder (PTSD) during the first 3-4 months after returning home (Hoge et al., 2004).

Research has demonstrated a positive association between traumatic exposures and PTSD among workers who practice high-risk activities, including firefighters (e.g., Wagner, Heinrichs, \& Ehlert, 1998), police (Robinson, Sigman, \& Wilson, 1997), and deployed soldiers (e.g., Bramsen, Dirkzwager, \& Van de Ploeg, 2000). There are also studies linking coping strategies to health outcomes among workers who were exposed to traumatic situations (Benotsch

*Correspondence to: Ann Chunyan Peng, Department of Management, Michigan State University, East Lansing, MI 48824, U.S.A.

E-mail: pengchu1@msu.edu 
et al., 2000; Brown, Mulhern, \& Joseph, 2002; Haisch \& Meyers, 2004). Avoidance coping (e.g., denying reality, using alcohol or drugs) is generally found to be maladaptive across a variety of traumatic situations (e.g., Benotsch et al., 2000; Chung, Farmer, Werrett, Easthope, \& Chung, 2001). However, the relationship between problemfocused coping and mental health symptoms is less evident; some studies find a negative association (e.g., Chung et al., 2001; Dougall, Hyman, Hayward, McFeeley, \& Baum, 2001), whereas other studies find no relationship (e.g., Stein, Tran, Lund, Dashevsk, \& Baker, 2005; Wolfe, Keane, Kaloupek, Mora, \& Wine, 1993).

Besides the inconsistent findings regarding the effectiveness of coping styles, there are also typical limitations to inferences made in this literature. First, existing research has relied upon recollections. Emergency workers and military personnel have been surveyed after their exposures to the traumatic events. For example, studies on soldiers coping with war-zone stress are limited largely to veterans who were seeking treatment (Benotsch et al., 2000). Retrospective reports are particularly problematic in this type of study because people who have been traumatized are unable to accurately recall the details of traumatic exposures either voluntarily or involuntarily (Lerias \& Byrne, 2003). With retrospective reports, it is also difficult to determine how individuals actually coped with the traumatic events in situ (Stone, Kennedy-Moore, \& Neale, 1995; Stone et al., 1998). This study examines soldiers' coping responses during deployment. Such research may prove critical to uncovering the risk factors associated with the development of PTSD and other mental health problems and potentially aid in identifying effective interventions before or during deployment (Farley \& Catano, 2006).

Little research has examined the role of personality in coping with extreme occupational stress. Given that coping with trauma can be very different from coping with daily-life stress (Aldwin \& Yancura, 2004), the extent to which personality influences coping in extreme situations such as deployment to a war zone is unclear. Hannah, Uhl-Bien, Avolio, and Cavarretta (2009) define an extreme context as

an environment where one or more extreme events are occurring or are likely to occur that may ... result in an extensive and intolerable magnitude of physical, psychological, or material consequences to-or in close physical or psycho-social proximity to-organization members (p. 898).

Studying workers in extreme contexts provides a unique opportunity to obtain frame-breaking findings that extend the current understanding of phenomena in organizations (Bamberger \& Pratt, 2010). By surveying soldiers during deployment, we contribute to the literature on personality and coping with daily stressors (Connor-Smith \& Flachsbart, 2007). This study also considers multiple personality dimensions, whereas previous research on personality and coping has focused disproportionally on neuroticism (Grant \& Langan-Fox, 2007).

Finally, by jointly examining personality, coping behavior, and cognitive appraisals of the environment in predicting psychological strain, we seek to extend the understanding of how people cope with long-lasting traumatic stressors. This study also addresses the call for research that moves beyond "simple correlations between broad measures of personality and coping" (Connor-Smith \& Flachsbart, 2007, p.1099). To our knowledge, this is the first study that examines to what extent, in what way, and under which conditions personality influences coping with traumatic occupational stress. Thus, in various ways, our study extends the literature that has primarily focused on the development of PTSD among workers facing extreme occupational stress by using data that are not retrospective, by incorporating coping behaviors, and by clarifying the role of personality traits in coping in such contexts.

\section{Literature Review and Hypotheses Development}

\section{Combat exposures, coping strategies, and psychological distress}

Soldiers in war zones face a wide range of life-threatening events, such as receiving direct or indirect fire, being the target of improvised explosive devices, seeing close friends seriously wounded or killed in theater, and personally killing or injuring enemy combatants. It is therefore not surprising that many researchers have demonstrated a 
positive association between combat exposures and psychological dysfunction among veterans (Bramsen et al., 2000; Hoge et al., 2006; Mehlum \& Weisæth, 2002; Stein et al., 2005). Nevertheless, most soldiers are able to adjust well after returning from war (Hoge et al., 2004; Hoge et al., 2006). Thus, what happens during the deployment experience that leads some soldiers to respond with resilience whereas others suffer from debilitating psychological disorders remains an open question.

Research therefore needs to focus on the impact of the military experiences on more general physical and psychological health of military members on active duty (Golembiewski, Aldinger, Munzenrider, \& Luo, 1998). This study examined general psychological distress by assessing symptoms such as somatization, obsessive-compulsive disorder, and psychoticism. Somatization is the process by which psychological distress is expressed as physical symptoms (Derogatis \& Melisaratos, 1983). Some of the more frequent symptoms are headaches, pain in the back or joints, difficulty swallowing or speaking, and problems with coordination of balance. Obsessive-compulsive disorder is a psychiatric disorder characterized by obsessive thoughts and compulsive actions, such as cleaning, checking, or counting that can persist throughout a person's life (American Psychiatric Association, 2000). Symptoms of psychoticism can range from mild forms (e.g., the presence of unusual feelings, thoughts, or behaviors) to extreme forms characterized by an absence of felt experience, inability to express emotions, and difficulty in speaking. Obsessive-compulsive disorder and psychoticism represent types of anxiety (Essau, Conradt, \& Petermann, 2002). These symptoms, albeit less frequently examined in the literature, have been found to be associated with a range of occupational stress such as prior-combat stress among soldiers (Bartone, 1999) and experiences of harassment at work (Bowling \& Beehr, 2006).

One factor that may differentiate those who do and do not suffer psychological dysfunction is the type of coping strategies the individual typically uses when encountering extreme conditions. Coping is defined as "constantly changing cognitive and behavioral efforts to manage specific external and/or internal demands that are appraised as taxing or exceeding the resources of the person" (Lazarus \& Folkman, 1984, p.141). For example, it is plausible that veterans who are least affected by war-zone experiences are those who coped with them effectively during their deployment. Studies have shown that soldiers who recalled using more avoidance coping strategies during their deployment were more likely to be diagnosed with PTSD later on (Benotsch et al., 2000; Stein et al., 2005; Wolfe et al., 1993).

We examined three broad categories of coping behavior including the following: (i) problem-focused (or active) coping, which is directed at managing or eliminating the stressor itself; (ii) avoidance coping that regulates behavior or thoughts to escape from the stressor; and (iii) seeking social support, which involves turning to others to release distress, solicit empathy (emotional social support), and seek solutions to one's problems from others (instrumental social support). There are many approaches to classifying the large number of coping strategies, and any single approach seems insufficient (Skinner, Edge, Altman, \& Sherwood, 2003). However, problem-focused coping and avoidance coping are found to be useful dimensions for distinguishing the various coping behaviors (Compas, Connor-Smith, Saltzman, Thomsen, \& Wadsworth, 2001; Folkman \& Moskowitz, 2004). Because it is unique in terms of involving utilizing resources in one's social network, seeking social support has been considered as a separate category of coping (Carver, Scheier, \& Weintraub, 1989; Connor-Smith \& Flachsbart, 2007; Fairbank, Hansen, \& Fitterling, 1991).

\section{Avoidance coping}

These three broad types of coping strategies (i.e., problem-focused coping, avoidance coping, and seeking social support) have been linked to different health consequences in the literature (see Folkman \& Moskowitz, 2004, for a review). Research examining a wide range of life stressors has consistently demonstrated that avoidance coping is positively associated with illness symptoms. In addition, studies of war veterans and incumbents of other dangerous occupations have found positive correlations between avoidance coping and poor health (Benotsch et al., 2000; Brown et al., 2002; Haisch \& Meyers, 2004). Avoiding the stressor may reduce one's anxiety in the short term (Suls \& Fletcher, 1985), but over time, it promotes distress (Begley, 1998; Tyler \& Cushway, 1995). Therefore, we expect that to the extent soldiers engage in avoidance coping during deployment, they will experience higher psychological distress and report more illness symptoms. 
Hypothesis 1a: Avoidance coping is positively related to psychological distress (i.e., anxiety and somatic complaints) among deployed soldiers.

\section{Problem-focused coping}

Problem-focused coping, which involves initiating a plan of action and focusing on situational demands, has been associated with decreased depression, anxiety, somatization (Greenglass \& Burke, 2000), and overall improved health (Parkes, 1990). Soldiers who engage in problem-focused coping seek out helpful information about their environment, and this enables intellectual and physical vigor in confronting challenging situations (Peterson \& Stunkard, 1989). This vigor and readiness may reduce the intensity of the traumatic stress that soldiers would otherwise experience. Problemfocused coping may also promote the perception that one has control over stressful encounters, and theory and research suggest that this will tend to reduce strain (Lazarus, 1991; Taylor \& Brown, 1988; Todrank Heth \& Somer, 2002).

\section{Seeking social support}

Similarly, individuals who seek out social support to help with managing stressors may also cope with traumatic stressors more effectively. In particular, seeking out instrumental social support can help solve the particular problem that is causing distress. Seeking emotional support is, in general, less salutary for health than is problem-focused coping because it does little to reduce the level of stressors (Compas et al., 2001; Folkman \& Moskowitz, 2004). Nevertheless, it can be an effective coping strategy in situations that provide few opportunities for control (Terry \& Hynes, 1998). Attaining a comfortable emotional state is also essential to actively manage ongoing stressors (Lazarus \& Folkman, 1984). For these reasons, we hypothesize that problem-focused coping and seeking social support will each be negatively related to distress.

Hypothesis 1b: Problem-focused coping is negatively related to psychological distress among deployed soldiers.

Hypothesis $1 c$ : Seeking social support is negatively related to psychological distress among deployed soldiers.

\section{Personality and coping with combat stress}

Personality is suggested to influence tendencies to engage in particular types of coping behaviors (e.g., Bolger, 1990; Connor-Smith \& Flachsbart, 2007; Gunthert, Cohen, \& Armeli, 1999; Parkes, 1990). Despite a plethora of studies on personality and coping with life stressors, little is known about the role of personality in coping with traumatic events (Aldwin \& Yancura, 2004). Where personality has been examined in studies of traumatic exposure, researchers have focused on the correlation of personality with illness symptoms (e.g., Haisch \& Meyers, 2004; Kneževic, Opacic, Savic, \& Priebe, 2005) and have not examined the underlying mechanisms such as coping behavior. Using the Five-Factor Model (FFM) of personality, we examined in this study how three dimensions of personality, namely neuroticism, conscientiousness, and extraversion, relate to the three general types of coping strategies reviewed earlier. Among various models of personality, FFM is the most popular and empirically validated structure of personality (McCrae \& Allik, 2002). We excluded the other two personality dimensions (i.e., agreeableness and openness) from our analyses for the following reasons. First, there is a clear theoretical match between the three personality dimensions of neuroticism, extraversion, and conscientiousness with the three aforementioned coping strategies (McCrae \& Costa, 1986; Vollrath \& Torgersen, 2000). Second, as reviewed by Grant and Langan-Fox (2006), compared with the other three dimensions, "Agreeableness and Openness are weakly related to coping. .." (p.721). Connor-Smith and Flachsbart also demonstrated in their quantitative review that agreeableness and openness are weaker predictors of broad coping strategies.

\section{Neuroticism}

Neuroticism is probably the mostly studied personality dimension in the stress coping literature. It reflects a tendency to feel distressed and nervous (George, 1989) and is associated with the experience and expression of 
negative emotions such as frustration (McCrae \& John, 1992). Although combat exposures may generate negative feelings in most individuals, those who are high in neuroticism may be expected to respond more negatively because they tend to be more pessimistic (Grant \& Langan-Fox, 2007; Suls \& Martin, 2005). As a result, they engage in more avoidance coping whereby they are mentally disengaged from reality and ruminate about their negative feelings. Perceiving that the situation is unlikely to improve also prevents such persons from taking actions directed toward solving their underlying problems. Consistent with this rationale, research has found a positive relationship between neuroticism and ineffective coping in various populations (Bolger, 1990; Gunthert, Cohen, \& Armeli, 1999; Murberg, 2009; Parkes, 1990).

\section{Extraversion}

Extraversion is a personality trait characterized by sociability, gregariousness, and assertiveness (McCrae \& John, 1992). Extraverted persons engage in more social activities and appear cheerful and energetic (Watson \& Clark, 1997). Their tendency to relate to and communicate with other individuals leads them to be more likely to seek out social support, and this may help them overcome experienced stress (Amirkhan, Risinger, \& Swickert, 1995; Parkes, 1990; Zellars \& Perrewé, 2001). In addition, extraverted persons tend to be more energetic than nonextraverts, and their vigor facilitates active coping (Holahan \& Moos, 1991). In support of these speculations, extraversion was found to be positively related to active coping and to seeking emotional and instrumental social support in a meta-analytical study (Connor-Smith \& Flachsbart, 2007).

\section{Conscientiousness}

Conscientiousness is composed of a set of traits such as prudence, self-regulation, persistence, achievement orientation, and seeking order that tend to make people more reliable and dependable in conventional situations (McCrae \& John, 1992). Facing a potentially stressful situation, conscientious people are more likely to perceive that they have control over the stressor (David \& Suls, 1999), and they are therefore motivated to make specific plans and effectively pool available resources to solve the problem (Bamberger \& Bacharach, 2006). In other words, the traits underlying conscientiousness should facilitate problem-focused coping. Conscientiousness should also be negatively related to avoidance coping because such coping reflects a sense of hopelessness and a lack of control and therefore a tendency to give up. These tendencies are very different from the behaviors that characterize more conscientious people. These observations suggest the following hypotheses for deployed soldiers:

Hypothesis $2 a$ : Neuroticism is positively associated with avoidance coping and negatively associated with problem-focused coping among deployed soldiers.

Hypothesis $2 b$ : Extraversion is positively associated with seeking social support and problem-focused coping among deployed soldiers.

Hypothesis 2c: Conscientiousness is positively associated with problem-focused coping and negatively associated with avoidance coping among deployed soldiers.

The linkages specified in Hypotheses 2a-c, which link personality to coping behavior, together with those specified in Hypotheses 1a-c (i.e., from coping to distress), encompass one potential mechanism that explains how personality influences health outcomes. However, there are other ways in which personality affects health. For example, Bolger and Zuckman (1995) have speculated that personality affects individuals' exposure to different stressors, their appraisals and reactions (e.g., coping choices) toward the stressors, and the effectiveness of their coping efforts. Because of the multiple mechanisms through which personality affects health, coping is not expected to fully explain the influence of personality on stress reactivity (Bolger \& Zuckerman, 1995). Therefore, we expect that coping only partially mediates the effect of personality on psychological distress. 
Hypothesis 3: Coping strategies partially mediate the relationships between personality and psychological distress among deployed soldiers.

\section{Threat appraisal as a moderator}

Research on stress and coping behavior has for some time focused on how individuals evaluate the dimensions of the stressor event, such as its threat potential. Cognitive appraisals are proposed to be a primary component of the coping process that may interact with methods of coping to influence adjustment to everyday stressors (Lazarus \& Folkman, 1984). In a recent study, researchers found threat appraisals to be an important antecedent of employee behavior in the context of change (Fugate, Prussia, \& Kinicki, in press). Such appraisals explained variation in individuals' experience and reaction to the same change event.

Feeling physically threatened is probably one of the most prevalent and intense appraisals made by soldiers in war zones and among others who are engaged in dangerous occupations. Traumatizing events are an inherent part of extreme occupations. They not only contribute directly to poor physical and psychological health, but the extent to which one's appraisal of them is threatening may also shape the effectiveness of particular coping strategies (Delongis \& Holtzman, 2005; Folkman \& Moskowitz, 2004). Although active coping and seeking out social support are generally beneficial, and avoidance coping is more often maladaptive (Hypotheses $1 \mathrm{a}-\mathrm{c}$ ), these relationships may be stronger under situations that are more threatening. Thus, the effect of coping on health becomes more visible as the level of stress increases. Supporting this, researchers have observed a stronger association between coping behaviors and health outcomes in situations characterized as being more stressful, both in normal daily life (Holahan \& Moos, 1991) and among deployed soldiers (Sharkansky et al., 2000; Suvak, Vogt, Savarese, King, \& King, 2002).

The level of perceived threat not only amplifies the relationship between coping and health but also strengthens the relationship between personality and coping (Aldwin \& Yancura, 2004). In their meta-analysis, Connor and Flachsbart (2007) found that personality has a stronger association with coping behavior in situations appraised as being more stressful (e.g., cancer, divorce). A stress-resilient personality (e.g., high extraversion, high conscientiousness, low neuroticism) should facilitate effective coping actions to a greater degree when the situation is more threatening. To summarize, we argue that more stressful situations strengthen both the association of personality with coping behavior and that of coping and distress. This suggests that the mediating effects of coping behaviors (Hypothesis 3) are stronger as the level of threat appraisal increases. Therefore, we hypothesized a moderated mediation effect regarding personality, coping, and psychological distress:

Hypothesis 4: The indirect effect of personality on psychological distress through coping behaviors is stronger when the level of perceived threat is higher.

\section{Method}

\section{Participants}

We surveyed US Army personnel from nine units (eight companies and one small battalion) as part of a larger study during their deployment in Iraq in the summer of 2004 (see also Schaubroeck, Riolli, Peng, \& Spain, 2011). A total of 648 soldiers completed the survey, with an overall response rate of 44.1 per cent. The participants were composed of (mean age=27.7, 99 per cent men), 70.4 per cent Caucasian, 11.9 per cent African-American, and10.2 per cent Hispanic; the remaining 7.5 per cent was composed of other ethnicities and individuals who did not report their ethnicity. The rank of soldiers varied: 56 per cent were junior enlisted personnel (e.g., private, specialist, corporal), 33 per cent were mid-grade non-commissioned officers (e.g., sergeant and staff sergeant), 5 per cent were senior non-commissioned 
officers (sergeant first class, master sergeant, and sergeant major), and 5 per cent were platoon and company grade officers (lieutenants and captains).

\section{Procedures}

We informed the soldiers of the purpose and procedure of the study before they were solicited to volunteer to participate. The participants provided informed consent, and we guaranteed them anonymity and confidentiality. The data collection took place during a one-month period in the summer of 2004. At that time, all the units sampled had been deployed to Iraq for at least two months. Although this period was after the conclusion of combat operations against the former army of Iraq, the US troops were very often engaged in heavy fighting against native and foreign insurgents.

\section{Measures}

\section{Psychological distress}

We measured psychological distress using three subscales from the Brief Symptom Inventory (Derogatis \& Melisaratos, 1983). These scales included the following: (i) somatization: distress arising from perceptions of bodily dysfunction ( $\alpha=.85,6$ items); (ii) obsessive-compulsiveness: thoughts, impulses, and actions that are experienced as unremitting ( $\alpha=.83,6$ items); and (iii) psychoticism: withdrawal, isolation, alienation $(\alpha=.74,5$ items). We instructed the participants to report their experience in the past few weeks of their deployment.

\section{Coping}

We used the COPE scale by Carver, Scheier and Weintraub (1989) to assess various coping behaviors in which the soldiers engaged during the past few weeks. We further classified these individual coping behaviors into three commonly identified coping styles (see Kammeyer-Mueller, Judge, \& Scott, 2009).

1. Problem-focused coping is to take active steps to remove or reduce the level of the current stressor or to ameliorate its effects. It includes active coping ( $\alpha=.70,5$ items), which concerns behaviors such as suppressing attention to potential distractions and initiating direct action to solve the problem; and planning $(\alpha=.81,4$ items), that is, developing and initiating strategies to resolve a stressful situation.

2. Avoidance coping consists of behavioral disengagement ( $\alpha=.78,4$ items), behavior or intentions to withdraw attention from the problem and to give up trying to resolve it; denial $(\alpha=.75,4$ items), refusing to believe that the stressor exists or trying to act as if the stressor is not real; and alcohol and drug use ( $\alpha=.93,4$ items), drinking or using drugs to blunt the feelings associated with exposure to the stressor.

3. Seeking social support includes behavior such as seeking help from friends, family, or other individuals or collectives in one's social network. It is composed of instrumental social support ( $\alpha=.76,4$ items), seeking tangible support from others to resolve the problem, such as by consulting them for their advice; and emotional social support $(\alpha=.81,4$ items), in which one seeks sympathy or understanding from important others.

\section{Personality}

We examined three personality constructs from the Big 5 personality cluster that have been found to be associated with different coping behaviors (Connor-Smith \& Flachsbart, 2007). Specifically, we measured conscientiousness, extraversion, and neuroticism using the 7-item scales developed by Fossum, Weyant, Etter, and Feldman-Barrett (1998). Conscientiousness $(\alpha=.80)$ refers to being diligent and responsible, following norms, seeking control, and striving for success. Extraversion $(\alpha=.76)$ refers to sociability, gregariousness, and an upbeat, assertive attitude. Neuroticism $(\alpha=.74)$ is often called "emotional stability" when reverse-scored; it measures an enduring tendency toward negative emotions, such as anxiety, hostility, and depression. 


\section{Threat appraisal}

We used the measure of threat appraisal from the appraisal of life events scale (Ferguson, Matthews, \& Cox, 1999). We asked the participants to appraise "your current military deployment" on six adjectives (e.g., hostile, potentially harmful) using a 6-point Likert scale ranging from 0 (not at all), to 5 (very much so). Coefficient alpha for the current sample was .92 .

\section{Control variables}

Age and education may be relevant control variables for a study of stress and well-being. However, they were not significantly correlated with any of the coping and health variables after soldier rank was entered in the model. Male participants predominantly ( 98 per cent) comprised the sample, and thus, we do not examine gender effects. Therefore, we controlled only for rank in the final analyses testing the hypotheses.

\section{Results}

We conducted a second-order confirmatory factor analysis to verify the higher-order factor structure of the coping strategies. The first model we tested specified the indicators (observed items) as loading on each coping strategy (e.g., planning, alcohol and drugs, emotional social support), and each individual coping strategy factor, in turn, loaded on one of the three higher-order latent factors (i.e., problem focused, avoidance, and seeking social support). This model indicated good fit to data, $\chi^{2}=820.02, d f=367, p<.01$, standardized root mean squared error of approximation $(R M S E A)=0.04$, comparative fit index $(C F I)=0.98$, and normed fit index $=0.96$. The indicators loaded on the specified first-order factor with coefficients ranging from 0.47 to 0.87 (average loading $=0.67$ ), and the first-order factors loaded on the hypothesized higher-order factors with loadings ranging from 0.58 to 0.99 .

We also compared the hypothesized model with the alternative first-order and second-order models. The results showed that among the first-order models, the 7-factor oblique model (i.e., with all items loading on hypothesized factors) fits the data better than the other alternative structures, thus showing the discriminant validity of the seven coping-behavior measures at the first level. In addition, our hypothesized second-order model fits the data well and performs better than the three alternative second-order models. These findings support our categorization of the three coping styles.

Table 1 shows the correlations among the studied variables. The sample means on the three illness symptoms were significantly larger $(p<.01)$ than the normative scores of the civilian sample reported by Derogatis and Melisaratos (1983) $(0.29,0.43$, and 0.15 for somatic complaints, obsessive-compulsion, and psychoticism, respectively, versus $0.58,1.04$, and 0.78 in the present sample). As expected, problem-focused coping was negatively related to all three illness symptoms, whereas avoidance coping was positively related to these symptoms. The three illness symptoms scales were quite highly correlated, and therefore, we used the mean score for each symptom scale to index a latent factor of "psychological distress" in the structural equations modeling (SEM) analyses. This is consistent with the literature that shows a general distress factor accounts most of the variance in the Brief Symptom Inventory dimensional scores (see Daoud \& Abojedi, 2010, for a review).

\section{Structural equation modeling results}

We tested the hypotheses using the SEM program LISREL 8.80 (Scientific Software International, Inc., Lincolnwood, IL) (Jöreskog \& Sörbom, 2006). We specified a latent factor model whereby three personality constructs were linked to the three coping-behavior composites, which were further linked to the distress factor. We examined the direct paths from personality to psychological distress in a partial mediation model. For these analyses, we randomly selected three items as indicators for each personality construct. The indicators for each of the three general 


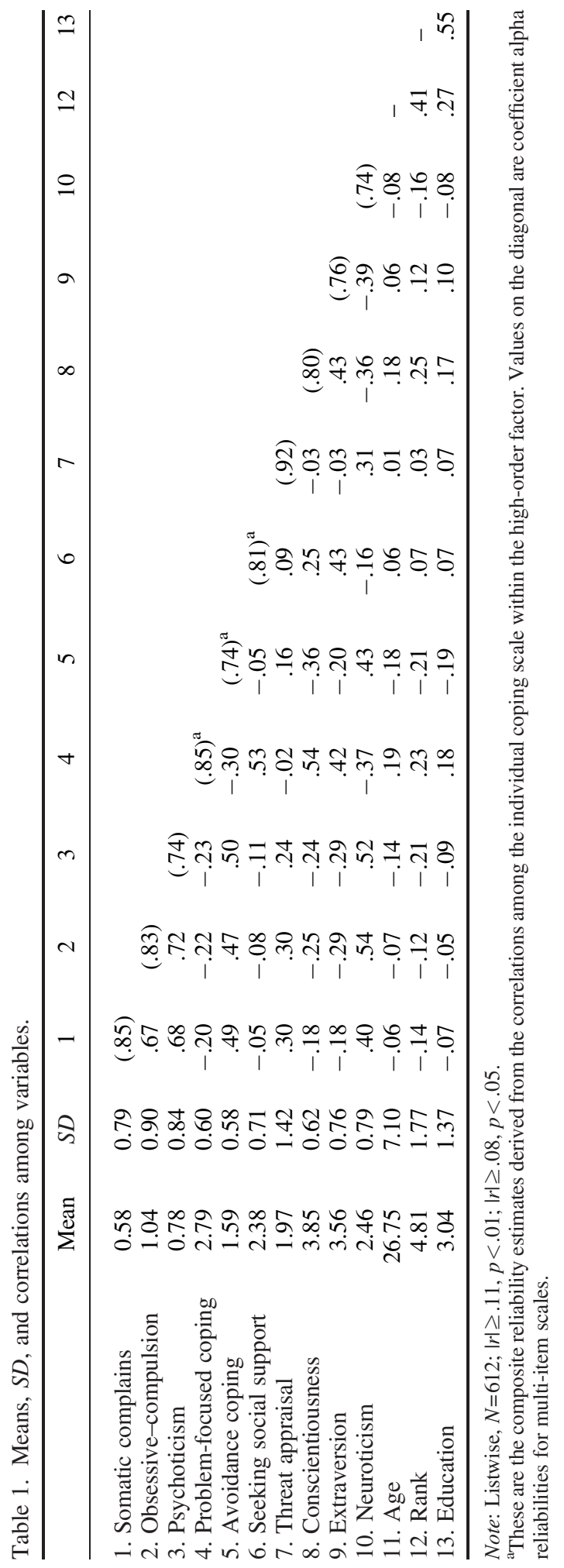


Table 2. Multi-group comparison analysis testing the moderating effect of threat appraisal.

\begin{tabular}{|c|c|c|c|c|c|c|c|c|}
\hline \multirow[b]{3}{*}{ From } & \multirow[b]{3}{*}{ To } & \multicolumn{2}{|c|}{ Overall sample } & \multicolumn{4}{|c|}{ Multi-group comparison } & \\
\hline & & \multirow[b]{2}{*}{$\begin{array}{c}\text { Path } \\
\text { coefficient }\end{array}$} & \multicolumn{3}{|c|}{ Total effect } & \multicolumn{3}{|c|}{ Indirect effect } \\
\hline & & & $\begin{array}{l}\text { High } \\
\text { threat } \\
\text { appraisal } \\
\text { group }\end{array}$ & $\begin{array}{l}\text { Low } \\
\text { threat } \\
\text { appraisal } \\
\text { group }\end{array}$ & Fisher $z$ & $\begin{array}{l}\text { High } \\
\text { threat } \\
\text { appraisal } \\
\text { group }\end{array}$ & $\begin{array}{l}\text { Low } \\
\text { threat } \\
\text { appraisal } \\
\text { group }\end{array}$ & Fisher $z$ \\
\hline \multicolumn{9}{|l|}{ (Personality $\rightarrow$ strain $)$} \\
\hline Conscientiousness & $\begin{array}{l}\text { Psychological } \\
\text { distress }\end{array}$ & 0.15 & 0.05 & 0.02 & 0.24 & -0.55 & 0.13 & $5.88 * *$ \\
\hline Extraversion & $\begin{array}{l}\text { Psychological } \\
\text { distress }\end{array}$ & $-0.14 *$ & -0.25 & 0.05 & $2.40 *$ & 0.22 & 0.11 & 0.89 \\
\hline Neuroticism & $\begin{array}{l}\text { Psychological } \\
\text { distress }\end{array}$ & $0.44 * *$ & 0.65 & 0.69 & 0.57 & 0.44 & 0.16 & $2.44 * *$ \\
\hline \multicolumn{9}{|c|}{ (Personality $\rightarrow$ coping) } \\
\hline Conscientiousness & $\begin{array}{l}\text { Problem-focused } \\
\text { coping }\end{array}$ & $0.58 * *$ & 0.62 & 0.64 & 0.26 & & & \\
\hline Conscientiousness & Avoidance coping & $-0.43 * *$ & -0.50 & -0.37 & 1.26 & & & \\
\hline Conscientiousness & $\begin{array}{l}\text { Seeking social } \\
\text { support }\end{array}$ & $0.22 * *$ & 0.14 & 0.21 & 0.57 & & & \\
\hline Extraversion & $\begin{array}{l}\text { Problem-focused } \\
\text { coping }\end{array}$ & 0.06 & 0.04 & 0.12 & 0.63 & & & \\
\hline Extraversion & Avoidance coping & $0.23 * *$ & 0.31 & 0.31 & 0.00 & & & \\
\hline Extraversion & $\begin{array}{l}\text { Seeking social } \\
\text { support }\end{array}$ & $0.29 * *$ & 0.34 & 0.28 & 0.52 & & & \\
\hline Neuroticism & $\begin{array}{l}\text { Problem-focused } \\
\text { coping }\end{array}$ & $-0.16 * *$ & -0.18 & -0.09 & 0.72 & & & \\
\hline Neuroticism & Avoidance coping & $0.52 * *$ & 0.51 & 0.56 & 0.55 & & & \\
\hline Neuroticism & $\begin{array}{l}\text { Seeking social } \\
\text { support }\end{array}$ & -0.08 & -0.29 & -0.09 & 1.63 & & & \\
\hline \multicolumn{9}{|l|}{ (Coping $\rightarrow$ illness) } \\
\hline $\begin{array}{l}\text { Problem-focused } \\
\text { coping }\end{array}$ & $\begin{array}{l}\text { Psychological } \\
\text { distress }\end{array}$ & 0.07 & -0.29 & 0.45 & $6.15^{* *}$ & & & \\
\hline Avoidance coping & $\begin{array}{l}\text { Psychological } \\
\text { distress }\end{array}$ & $0.47 * *$ & 0.75 & 0.33 & $4.94 * *$ & & & \\
\hline Social support & $\begin{array}{l}\text { Psychological } \\
\text { distress }\end{array}$ & -0.04 & -0.01 & -0.18 & 1.35 & & & \\
\hline
\end{tabular}

Note. $N($ overall sample $)=633 . N($ high threat appraisal group $)=133$, and $N($ low threat appraisal group $)=120$.

$* p<.05$.

$* * p<.01$.

coping strategies were the means of their respective coping scales (e.g., active coping, behavioral disengagement, seeking emotional social support).

The fit indices for the partial mediation model were acceptable, $\chi^{2}=359.85, d f=131, p<.01 ; R M S E A=0.05 ; C F I=$ 0.98; GFI=0.94. Therefore, we examined each path coefficient in this model to test Hypotheses 1 and 2. Table 2 shows these path coefficients under the column labeled "overall sample." As expected, avoidance coping was positively related to psychological distress $(\beta=.47, p<.01)$, supporting Hypothesis 1a. Neither problem-focused coping nor seeking social support was related to distress, and therefore Hypotheses $1 \mathrm{~b}$ and $\mathrm{c}$ are not supported. Personality constructs were related to coping behavior in the predicted directions, with one exception being that extraversion was not related to problem-focused coping. Overall, the results generally support Hypotheses $2 \mathrm{a}-\mathrm{c}$. 
Table 3. Hierarchical regression results testing interaction of coping with threat appraisal in predicting illness symptoms.

\begin{tabular}{|c|c|c|c|c|c|c|c|c|c|}
\hline \multirow{3}{*}{$\begin{array}{l}\text { Model } \\
\text { Step } 1\end{array}$} & \multicolumn{9}{|c|}{ Standardized regression coefficients ${ }^{\mathrm{a}}$} \\
\hline & \multicolumn{3}{|c|}{ Somatic complaints } & \multicolumn{3}{|c|}{ Obsessive-compulsion } & \multicolumn{3}{|c|}{ Psychoticism } \\
\hline & $\mathbf{P F}^{\mathbf{b}}$ & $\mathbf{A} \mathbf{V}^{\mathbf{b}}$ & $\mathbf{S S}^{\mathbf{b}}$ & $\mathbf{P F}^{\mathbf{b}}$ & $\mathbf{A} \mathbf{V}^{\mathbf{b}}$ & $\mathbf{S S}^{\mathbf{b}}$ & $\mathbf{P F}^{\mathrm{b}}$ & $\mathbf{A} \mathbf{V}^{\mathbf{b}}$ & $\mathbf{S S}^{\mathbf{b}}$ \\
\hline Rank & -0.07 & -0.07 & -0.07 & -0.02 & -0.02 & -0.02 & $-0.13 * *$ & $-0.13 * *$ & $-0.13 * *$ \\
\hline Conscientiousness & -0.03 & -0.03 & -0.03 & -0.04 & -0.04 & -0.04 & -0.02 & -0.02 & -0.02 \\
\hline Neuroticism & $0.39 * *$ & $0.39 * *$ & $0.39 * *$ & $0.49 * *$ & $0.49 * *$ & $0.49 * *$ & $0.46^{* *}$ & $0.46^{* *}$ & $0.46^{* *}$ \\
\hline Extraversion & -0.01 & -0.01 & -0.01 & $-0.08 *$ & $-0.08^{*}$ & $-0.08 *$ & $-0.08^{*}$ & $-0.08 *$ & $-0.08 *$ \\
\hline Changes in $R^{2}$ & $0.18 * *$ & $0.18^{* *}$ & $0.17 * *$ & $0.31 * *$ & $0.31 * *$ & $0.31 * *$ & $0.30 * *$ & $0.30 * *$ & $0.30 * *$ \\
\hline \multicolumn{10}{|l|}{ Step 2} \\
\hline Threat appraisal & $0.21 * *$ & $0.18 * *$ & $0.21 * *$ & $0.16 * *$ & $0.14 * *$ & $0.16 * *$ & $0.11 * *$ & $0.12 * *$ & $0.12 * *$ \\
\hline $\begin{array}{l}\text { Problem-focused } \\
\text { coping (PF) }\end{array}$ & -0.06 & & & 0.03 & & & 0.01 & & \\
\hline $\begin{array}{l}\text { Avoidance } \\
\text { coping (AV) }\end{array}$ & & $0.38 * *$ & & & $0.29 * *$ & & & $0.09 * *$ & \\
\hline $\begin{array}{l}\text { Seeking social } \\
\text { support (SS) }\end{array}$ & & & -0.00 & & & 0.02 & & & -0.01 \\
\hline Changes in $R^{2}$ & $0.04 * *$ & $0.15 * *$ & $0.04 * *$ & $0.02 * *$ & $0.09 * *$ & $0.02 * *$ & $0.01 * *$ & $0.10 * *$ & $0.01 * *$ \\
\hline \multicolumn{10}{|l|}{ Step 3} \\
\hline $\begin{array}{l}\text { Threat appraisal } \\
\times \mathrm{PF}\end{array}$ & $-0.15^{* *}$ & & & $-0.08 *$ & & -0.06 & $-0.12 * *$ & & \\
\hline $\begin{array}{l}\text { Threat appraisal } \\
\times \mathrm{AV}\end{array}$ & & $0.18 * *$ & & & $0.08 * *$ & & & $0.08 * *$ & \\
\hline $\begin{array}{l}\text { Threat appraisal } \\
\times \mathrm{SS}\end{array}$ & & & $-0.09 *$ & & & & & & -0.06 \\
\hline Changes in $R^{2}$ & $0.02 * *$ & $0.03 * *$ & $0.01 *$ & $0.01 * *$ & $0.01 * *$ & 0.00 & $0.02 * *$ & $0.01 * *$ & 0.00 \\
\hline
\end{tabular}

Note. Each column denotes one set of analyses whereby one coping style variable (PF, AV, or SS) was included.

${ }^{a}$ Coefficients presented are at the point of the variables' entry into the regression equation.

${ }^{\mathrm{b}} \mathrm{PF}$, problem-focused coping; AV, avoidance coping; and SS, seeking social support.

$* p<.05$.

$* * p<.01$.

To examine the mediating role of coping as per Hypothesis 3, we compared the full-mediation model (Mf) with paths from personality to coping and from coping to distress, the non-mediation model $(M n)$, in which personality was linked directly to both coping and distress, and the partial mediation model $(M p)$, in which personality was linked to coping and distress, and coping also has a direct path to distress. Compared with $M p$, the model fit of $M f$ deteriorates $\left(\Delta \chi_{(M f-M p)}^{2}=65.88, d f=3, p<.01\right)$ by omitting the direct paths from personality to distress.

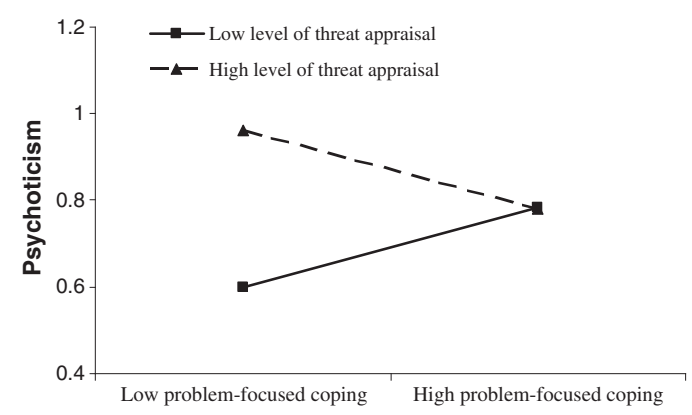

Figure 1. Interaction of problem-focused coping and threat appraisal in predicting psychoticism 


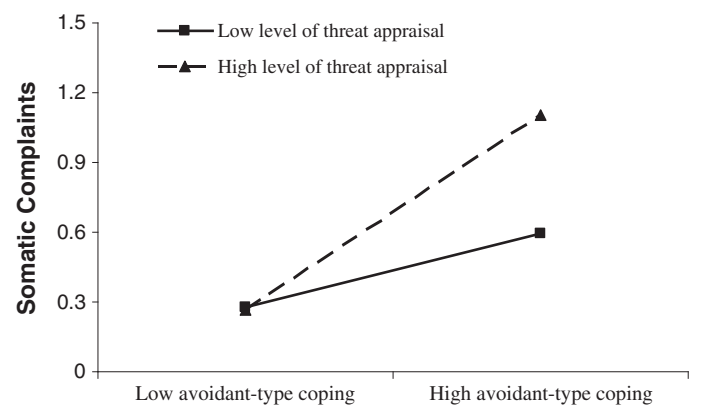

Figure 2. Interaction of avoidance coping and threat appraisal in predicting somatic complaints

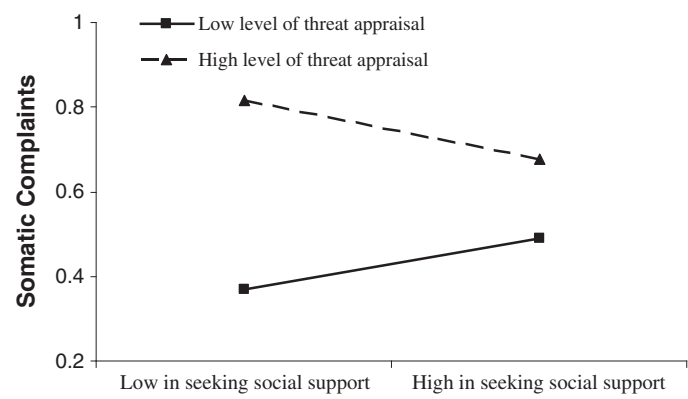

Figure 3. Interaction of seeking social support and threat appraisal in predicting somatic complaints

Excluding the paths from coping to illness in $M n$ reduces the model fit significantly $\left(\Delta \chi_{(M n-M p)}^{2}=40.37, d f=3, p\right.$ .01 ). The results indicated that $M p$ is better supported than the other two models. Therefore, Hypothesis 3 is supported.

To test the moderated mediation effect specified in Hypothesis 4, we conducted multi-sample comparison analyses using LISREL. These analyses examined whether the mediating effects of coping styles varied across individuals who perceived high or low threat. We grouped individuals into high and low threat categories on the basis of their reports of threat appraisal. Persons with scores of at least $1 S D$ above the sample mean were in the "high threat group" $(N=131)$, and those with scores at least $1 S D$ below the sample mean were in the "low threat group" $(N=128)$. The sample mean of threat appraisal in the high threat group was 4.09. This is significantly higher than that in the low threat group (Mean $=0.22, t=71.96, p<.01$ ).

We tested measurement invariance (i.e., factor loading and intercept invariance) across the high and low threat groups. This analysis shows that measures of personality and coping are equivalent across the two groups, but the factor loadings for the distress latent variable were different between the two groups. Therefore, we constrained the measurement models of personality and coping to be equal across the two groups while keeping the measurement parameters freely estimated for psychological distress.

The two-group comparison model exhibits a good fit, $\chi^{2}=356.43, d f=270, p<.01 ; R M S E A=0.05 ; C F I=0.97$. Table 2 presents the results for the total and indirect effects of personality on distress for the high and low threat subsamples. The $t$-tests indicate that the relationships between personality dimensions and coping behavior did not differ between high and low threat groups. In contrast, coping was differentially related to distress across the two groups. Overall, the indirect effects of personality through coping were stronger for all the personality constructs in the high-perceived threat group, although the difference between high and low threat subsamples was not significant for extraversion. The results, therefore, largely support Hypothesis 4, in that coping mediated the relationship between personality and strain to a greater degree as the level of perceived threat increased. 


\section{Supplementary analyses}

We conducted hierarchical regressions to further test the interactions of threat with coping in influencing psychological distress. This analysis complements the SEM analyses by examining threat appraisal as a continuous variable instead of dichotomizing it as in the SEM analyses. However, we separately examined each dependent variable in these analyses. This is appropriate considering that anxiety is theoretically and empirically distinct from somatic complaints (Derogatis, 2001). As shown in Table 3, the results are consistent with the SEM findings reported earlier. Perceived threat moderated the effects of problem-focused coping and of avoidance coping on all three illness symptoms. In addition, our findings suggest meaningful differences among the three symptoms. For example, personality variables explain almost 30 per cent of the variance in anxiety (i.e., obsessive-compulsive disorder and psychoticism), which is twice as large as that for somatic complaints. Between these anxiety symptoms, avoidance coping was more strongly associated with obsessive-compulsiveness than with psychoticism.

To examine the patterns of the interactions, we plotted each of the seven significant interactions. Because the interactions involving the same coping variable were found to share the same pattern across three illness symptoms, we present three representative interactions, with one plot for each coping variable (Figures 1 to 3). As shown in Figure 1, problem-focused coping is negatively related to reports of psychoticism when the perceived threat is high, but it is positively related to psychoticism when the threat is low. The level of threat amplifies the negative association of avoidance coping with somatic complaints such that avoidance coping is more maladaptive when the perceived threat is higher (Figure 2). Similar to the pattern shown in Figure 1, seeking out social support appears to be beneficial only among soldiers who perceive higher levels of threat Figure 3.

\section{Discussion}

In this study, we tested a model that links personality to coping and distress on a sample of military personnel deployed in Iraq during a peak period in the fighting. Our findings were consistent with the literature that has demonstrated adverse effects of avoidance coping in predicting PTSD symptomatology and other measures of psychological strain among soldiers who had returned from deployment (e.g., Benotsch et al., 2000; Stein et al., 2005). Avoidance coping was even more detrimental among soldiers who perceived higher levels of threat. Our findings further suggest that coping strategies partially mediate the effects of personality traits on psychological distress.

Problem-focused coping was found to be beneficial to health when the environment was perceived to be highly threatening, but it increased levels of distress among those with lower threat appraisal. Our findings differ from suggestions in a study by Terry and Hynes (1998) that problem-focused coping is less constructive in situations characterized as being low in control. However, Terry and Hynes surveyed women coping with the failed attempt of in vitro fertilization treatment. Trying hard to solve the problem may have reflected the participant's strong desire to be able to become pregnant, and these efforts would often lead to further frustration. In our study, although the soldiers cannot avoid being exposed to dangerous situations, engaging in problem-focused coping may enable them to be better prepared, mentally and physically, for the challenges of deployment. Problem-oriented behavior should also help soldiers maintain higher morale during the extended stress of deployment.

Surprisingly, our study also found a positive effect of problem-focused coping on distress among soldiers who perceived low levels of threat. Soldiers who perceived relatively low threat may have experienced quite different stressors compared with those with high threat appraisal. For example, they may have been more concerned about being isolated from their families, and perhaps, they were more bored by their duties (Bartone, Adler, \& Vaitkus, 1998). Consequently, engaging in problem-solving would be less useful. Future studies need to distinguish among different types of stressors and examine how multiple characteristics of the situation (e.g., controllability, stressfulness, significance) affect coping effectiveness.

Conversely, seeking social support was only helpful among soldiers who perceived a low level of threat. This finding might provide a potential explanation for the mixed findings of positive and negative consequences of 
seeking social support in previous research (DeLongis \& Holtzman, 2005; Zellars \& Perrewé, 2001). It is likely that a highly stressful situation promotes sharing and communicating negative emotions that reinforce an individual's distress (Zellars \& Perrewé, 2001). This merits additional research because it suggests a social information processing perspective (Salancik \& Pfeffer, 1978) on the stress-coping process under circumstances that workers are exposed to common stressors that presage intense anxiety.

Exposure to traumatic events in which a person experiences actual or threatened death or serious injury can produce significant physical and psychological illness symptoms (LeBlanc \& Kelloway, 2002). Such exposures are prevalent among military personnel who are deployed in war zones. Military deployments therefore provide a unique opportunity to study large groups of individuals who are commonly exposed to environments characterized by relatively unrelenting exposures to events that are potentially traumatic (Jermier, Gaines, \& McIntosh, 1989). Such contexts are thus an opportunity for researchers to better understand how people cope with traumatic situations in general, such as the onset of a potentially life-threatening illness, daily dangers that confront many police and fire personnel and other first responders and their loved ones, and work in other extreme environments (e.g., commercial fishing in rough waters).

\section{Practical implications}

From a practical perspective, our results suggest that it may be prudent to train workers in jobs that contain physical dangers and other potentially traumatic exposures to flexibly utilize different strategies to cope with stressors. For example, combat leaders can encourage soldiers to focus on active, problem-focused coping when lethal combat is imminent. This means finding some aspects of life over which one can have personal control. Identifying those targets of discretion and actively planning ways to resolve them may help workers in such hazardous environments to maintain a sense of control, even while the larger events that come to characterize the broader working environment are not controllable. In addition, learning to seek out social support from peers or their leaders may help workers cope with other stressors that accompany such work, such as the separation from family experienced by deployed soldiers.

The findings of this study may also inform the design of psychological resilience development programs such as the US Army's comprehensive soldier fitness (CSF) program (Casey, 2011; Cornum, Matthews, \& Seligman, 2011). The CSF program is a long-term preventive strategy to reduce the negative consequences of combat exposures among the army personnel by enhancing positive traits, emotions, institutions, and positive social relationships (Cornum et al., 2011). It suggests that understanding the specific stressors faced by an individual is important for choosing the types of support or training to provide. Thus, the CSF program or other similar training programs may train the participants to be more cognizant of and better express their difficulties so that leaders or other members can be more helpful. In addition, we suggest that leaders can be a critical resource in combat or other extreme situations because they can promote a shared positive unit climate that is powerful in influencing individual's interpreting the situation as well as adopting more effective coping strategies (Bartone, 2006). This reinforces the need for organizations to focus on developing effective leaders, in particular, when resources (e.g., time, personnel) are limited to develop the resilience of each employee.

There are also some implications for personnel selection. Our study suggests that personality traits associated with active, problem-focused coping may help distinguish those who use more effective approaches to managing fear and anxiety that is endemic to the work in extreme occupations. If militaries and others who operate in extreme conditions seek to engineer their personnel selection and classification systems, then personality traits associated with active coping (e.g., low level of neuroticism and high levels of conscientiousness) might prove to be useful components of selection batteries. This is especially important because personality factors (e.g., conscientiousness) are found to be valuable predictors of job performance as well (Barrick \& Mount, 1991; Hurtz \& Donovan, 2000).

\section{Limitations and future research}

Among the possible limitations of this study, it is not clear whether our findings concerning personality and coping behavior will generalize to less extreme organizational settings. Stress encountered by military personnel can be 
more intense than one typically encounters in other working populations. However, there are evident parallels between certain specific findings and those obtained in less extreme environments. For example, the linkages between personality variables and coping strategies are comparable with those reported in the meta-analysis reported by Connor and Flachsbart (2007). In addition, male participants entirely comprised our sample, and how the findings generate to female participants warrants further investigation (Tamres, Janicki, \& Helgeson, 2002).

We obtained our data from self-reports. As such, they may be subjected to individual differences in how subjects interpret the questions and how much self-awareness each may have about his or her emotional and mental states. Future research may benefit by also measuring the various stressors that refer to specific or general events that may have evoked different levels of threat appraisal. This would help determine how specific events translate into risks for emotional and physical distress. Our data were cross-sectional, and thus the findings may be subjected to common method bias. Yet, the fact that our correlation matrix was mixed with positive, negative, and non-significant coefficients lessens this concern (Spector, 2006). In addition, the findings of the interactive effects, however, are not expected to be spuriously inflated by common method variance (Evans, 1985). Nevertheless, we are limited in determining the causes and effects among personality, coping, and health. Future studies could profitably track individuals in hazardous occupations over time to establish the causal linkages and to better understand their course of adjustment.

Another limitation of this study is the sole focus on the second-order factors of FFM. Assessing the 30 facets of FFM allows a more sensible measure of personality that can account for additional variation in the coping behavior that is not explained by the five factors (Paunonen \& Ashton, 2001). For example, the propensity to trust others, one facet of agreeableness, may be associated with seeking social support, even though no relationship was found for the overall factor of agreeableness (e.g., Brebner, 2001). Future studies might also examine whether personality measures obtained before deployment are related to coping during deployment in ways similar to those observed in this study.

\section{Conclusion}

To our knowledge, this is the first study to test the moderated mediation effects of coping strategies with stress appraisals to predict psychological distress. The study is particularly novel because the data were collected during an extended period of potentially traumatizing stressors. We found that indirect effects of personality on illness symptoms can be explained more fully by coping styles among soldiers who appraised the environment as being more threatening, thus indicating a more critical role of the coping styles in extreme situations. The complicated effect of problem-focused coping on health suggests that future research should examine specific context and stressors to better understand stress-coping processes among employees in extreme occupations.

\section{Author biographies}

Ann Chunyan Peng is a Doctoral student of Management at Michigan State University. She received a research Master Degree (Mphil, Master in Philosophy) from Lingnan University of Hong Kong. Her current research interests include work stress and employee well-being, leadership and team dynamics, and proactive work behavior.

Laura T. Riolli is a Professor of Management at California State University Sacramento. She currently serves in the editorial board of Journal of Leadership and Organizational Studies. She received her Ph.D. from University Nebraska Lincoln in 1998. Her research interests include employee well-being and stress, organizational culture, and international management. 
John Schaubroeck is John A. Hannah Distinguished Professor of Psychology and Management at Michigan State University. He currently serves as Editor of Organizational Behavior and Human Decision Processes. He received his Ph.D. from Purdue University in 1988. His research interests include employee stress and well-being, leadership, and judgment processes in human resource contexts.

Lieutenant Colonel Everett S. P. Spain is the commander of the US Army Garrison in Schweinfurt, Germany. He is a distinguished graduate of West Point, earned an MBA from Duke's Fuqua School, and has served in Kosovo and Iraq. His research interests include leading change, transformational leadership, mentoring, and talent spotting.

\section{References}

Aldwin, C. M., \& Yancura, L. A. (2004). Coping and health: A comparison of the stress and trauma literatures. In P. P. Schnurr \& B. L. Green (Eds.), Trauma and health: Physical health consequences of exposure to extreme stress (pp. 99-126). Washington, DC: American Psychological Association.

American Psychiatric Association. (2000). Diagnostic and statistical manual of mental disorders (4th edition). Washington, DC: American Psychiatric Association.

Amirkhan, J. H., Risinger, R. T., \& Swickert, R. J. (1995). A “hidden” personality factor in coping? Journal of Personality, 63, 189-212.

Bamberger, P. A., \& Bacharach, S. B. (2006). Abusive supervision and subordinate problem drinking: Taking resistance, stress and subordinate personality into account. Human Relations, 59, 723-752.

Bamberger, P. A., \& Pratt, M. G. (2010). From the editors: Moving forward by looking back: Reclaiming unconventional research contexts and samples in organizational scholarship. The Academy of Management Journal, 53, 665-671.

Barrick, M. R., \& Mount, M. K. (1991). The Big five personality dimensions and job performance: A meta-analysis. Personnel Psychology, 44, 1-26.

Bartone, P. T. (1999). Hardiness protects against war-related stress in Army reserve forces. Consulting Psychology Journal, 51, 72-82.

Bartone, P. T. (2006). Resilience under military operational stress: Can leaders influence hardiness? Military Psychology, 18, 131-148.

Bartone, P. T., Adler, A. B., \& Vaitkus, M. A. (1998). Dimensions of psychological stress in peacekeeping operations. Military Medicine, 163, 587-593.

Begley, T. M. (1998). Coping strategies as predictors of employee distress and turnover after an organizational consolidation: A longitudinal analysis. Journal of Occupational and Organizational Psychology, 71, 305-330.

Benotsch, E. G., Brailey, K., Vasterling, J. J., Uddo, M., Constans, J. I., \& Sutker, P. B. (2000). War zone stress, personal and environmental resources, and PTSD symptoms in Gulf War veterans: A longitudinal perspective. Journal of Abnormal Psychology, 109, 205-213.

Bolger, N. (1990). Coping as a personality process: A prospective study. Journal of Personality and Social Psychology, 59, 525-537.

Bolger, N., \& Zuckerman, A. (1995). A framework for studying personality in the stress process. Journal of Personality and Social Psychology, 69, 890-902.

Bowling, N. A., \& Beehr, T. A. (2006). Workplace harassment from the victim's perspective: A theoretical model and metaanalysis. Journal of Applied Psychology, 91(5), 998-1012.

Bramsen, I., Dirkzwager, A. J. E., \& Van der Ploeg, H. M. (2000). Predeployment personality traits and exposure to trauma as predictors of posttraumatic stress symptoms: A prospective study of former peacekeepers. American Journal of Psychiatry, 157, 1115-1119.

Brebner, J. (2001). Personality and stress coping. Personality and Individual Differences, 31, 317-327.

Brown, J., Mulhern, G., \& Joseph, S. (2002). Incident-related stressors, locus of control, coping, and psychological distress among firefighters in Northern Ireland. Journal of Traumatic Stress, 15, 161-168.

Carver, C. S., Scheier, M. F., \& Weintraub, J. K. (1989). Assessing coping strategies: A theoretically based approach. Journal of Personality and Social Psychology, 56, 267-283.

Casey, G. W. Jr. (2011). Comprehensive soldier fitness: A vision for psychological resilience in the US Army. American Psychologist, 66, 1-3.

Chung, M. C., Farmer, S., Werrett, J., Easthope, Y., \& Chung, C. (2001). Traumatic stress and ways of coping of community residents exposed to a train disaster. Australian and New Zealand Journal of Psychiatry, 35, 528-534.

Compas, B. E., Connor-Smith, J. K., Saltzman, H., Thomsen, A. H., \& Wadsworth, M. E. (2001). Coping with stress during childhood and adolescence: Problems, progress, and potential in theory and research. Psychological Bulletin, 127, 87-127. 
Connor-Smith, J. K., \& Flachsbart, C. (2007). Relations between personality and coping: A meta-analysis. Journal of Personality and Social Psychology, 93, 1080-1107.

Cornum, R., Matthews, M. D., \& Seligman, M. E. P. (2011). Comprehensive soldier fitness: Building resilience in a challenging institutional context. American Psychologist, 66, 4-9.

Daoud, F. S., \& Abojedi, A. A. (2010). Equivalent factorial structure of the Brief Symptom Inventory (BSI) in clinical and nonclinical Jordanian populations. European Journal of Psychological Assessment, 26, 116-121.

David, J. P., \& Suls, J. (1999). Coping efforts in daily life: Role of Big Five traits and problem appraisals. Journal of Personality, 67, 265-294.

DeLongis, A., \& Holtzman, S. (2005). Coping in context: The role of stress, social support, and personality in coping. Journal of Personality, 73, 1633-1656.

Derogatis, L. R., \& Melisaratos, N. (1983). The Brief Symptom Inventory: An introductory report. Psychological Medicine, 13, 595-605.

Dougall, A. L., Hyman, K. B., Hayward, M. C., McFeeley, S., \& Baum, A. (2001). Optimism and traumatic stress: The importance of stress and coping. Journal of Applied Social Psychology, 31, 223-245.

Essau, C. A., Conradt, J., \& Petermann, F. (2002). Course and outcome of anxiety disorders in adolescents. Journal of Anxiety Disorders, 16, 67-81.

Evans, M. G. (1985). A Monte Carlo study of the effects of correlated method variance in moderated multiple regression analysis. Organizational Behavior and Human Decision Processes, 36, 305-323.

Fairbank, J. A., Hansen, D. J., \& Fitterling, J. M. (1991). Patterns of appraisal and coping across different stressor conditions among former prisoners of war with and without posttraumatic stress disorder. Journal of Consulting and Clinical Psychology, 59, 274-281.

Farley, K. M. J., \& Catano, V. M. (2006). The battlefield as workplace: Violence in warfighting In E. K. Kelloway, J. Barling \& J. Hurrell (Eds.), Handbook of workplace violence (pp. 281-308). Thousand Oaks, CA: Sage.

Ferguson, E., Matthews, G., \& Cox, T. (1999). The appraisal of life events (ALE) scale: Reliability and validity. British Journal of Health Psychology, 4, 97-116.

Folkman, S., \& Moskowitz, J. (2004). Pitfalls and promise. Annual Review of Psychology, 55, 745-774.

Fossum, T. A., Weyant, S. A., Etter, L., \& Feldman-Barrett, L. (1998). A short and simple alternative to long personality questionnaires. Poster session presented at the annual meeting of the American Psychological Society, Washington, DC.

Fugate, M., Prussia, G. E., \& Kinicki, A. J. (in press). Managing employee withdrawal during organizational change: The role of threat appraisal. Journal of Management. doi: 10.1177/0149206309352881.

George, J. M. (1989). Mood and absence. Journal of Applied Psychology, 74, 317-324.

Golembiewski, R.T., Aldinger, R.T., Munzenrider, R. \& Luo, H. (1998). Elaborating on the theme of 'OD as applied behavioral science': Burnout and mental health in a military population. Public Administration Quarterly, 21, 507-528.

Grant, S, \& Langan-Fox, J. (2006). Occupational stress, coping and strain: The combined/interactive effect of the Big Five traits. Personality and Individual Differences, 41, 719-732.

Grant, S., \& Langan-Fox, J. (2007). Personality and the occupational stressor-strain relationship: The role of the Big Five. Journal of Occupational Health Psychology, 12, 20-33.

Greenglass, E. R., \& Burke, R. J. (2000). Hospital downsizing, individual resources, and occupational stressors in nurses. Anxiety, Stress \& Coping, 13, 371-390.

Gunthert, K. C., Cohen, L. H., \& Armeli, S. (1999). The role of neuroticism in daily stress and coping. Journal of Personality and Social Psychology, 77, 1087-1100.

Haisch, D. C., \& Meyers, L. S. (2004). MMPI-2 assessed post-traumatic stress disorder related to job stress, coping, and personality in police agencies. Stress and Health, 20, 223-229.

Hannah, S. T., Uhl-Bien, M., Avolio, B. J., \& Cavarretta, F. L. (2009). A framework for examining leadership in extreme contexts. The Leadership Quarterly, 20, 897-919.

Hoge, C. W., Auchterlonie, J. L., \& Milliken, C. S. (2006). Mental health problems, use of mental health services, and attrition from military service after returning from deployment to Iraq or Afghanistan. Jama, 295, 1023-1032.

Hoge, C. W., Castro, C. A., Messer, S. C., McGurk, D., Cotting, D. I., \& Koffman, R. L. (2004). Combat duty in Iraq and Afghanistan, mental health problems, and barriers to care. The New England Journal of Medicine, 351, $13-22$.

Holahan, C. J., \& Moos, R. H. (1991). Life stressors, personal and social resources, and depression: A 4-year structural model. Journal of Abnormal Psychology, 100, 31-38.

Hurtz, G. M., \& Donovan, J. J. (2000). Personality and job performance: The Big Five revisited. Journal of Applied Psychology, $85,869-879$.

Jermier, J. M., Gaines, J., \& McIntosh, N. J. (1989). Reactions to physically dangerous work: A conceptual and empirical analysis. Journal of Organizational Behavior, 10, 15-33.

Jöreskog, K. G., \& Sörbom, D. (2006). LISREL 8.80 for Windows [computer software]. Lincolnwood, IL: Scientific software international, Inc. 
Kammeyer-Mueller, J. D., Judge, T. A., \& Scott, B. A. (2009). The role of core self-evaluations in the coping process. Journal of Applied Psychology, 94, 177-195.

Kneževic, G., Opacic, G., Savic, D., \& Priebe, S. (2005). Do personality traits predict post-traumatic stress? A prospective study in civilians experiencing air attacks. Psychological Medicine, 35, 659-663.

Lazarus, R. S. (1991). Emotion and adaptation. New York: Oxford.

Lazarus, R. S., \& Folkman, S. (1984). Stress, appraisal, and coping. New York: Springer Publishing.

LeBlanc, M. M., \& Kelloway, E. K. (2002). Predictors and outcomes of workplace violence and aggression. Journal of Applied Psychology, 87, 444-453.

Lerias, D., \& Byrne, M. K. (2003). Vicarious traumatization: Symptoms and predictors. Stress and Health, 19, $129-138$.

Litz, B. T. (2007). Research on the impact of military trauma: Current status and future directions. Military Psychology, 19, 217-238.

McCrae, R. R., \& Allik, J. (Eds.). (2002). The Five-Factor Model of personality across cultures. New York: Kluwer Academic.

McCrae, R. R., \& Costa Jr, P. T. (1986). Personality, coping, and coping effectiveness in an adult sample. Journal of Personality, 54, 385-404.

McCrae, R. R., \& John, O. P. (1992). An introduction to the Five-Factor model and its applications. Journal of Personality, 60, 175-215.

Mehlum, L., \& Weisæth, L. (2002). Predictors of posttraumatic stress reactions in Norwegian UN peacekeepers 7years after service. Journal of Traumatic Stress, 15, 17-26.

Murberg, T. A. (2009). Associations between personality and coping styles among Norwegian adolescents. Journal of Individual Differences, 30, 59-64.

Parkes, K. R. (1990). Coping, negative affectivity, and the work environment: Additive and interactive predictors of mental health. Journal of Applied Psychology, 75, 399-409.

Paunonen, S. V., \& Ashton, M. C. (2001). Big Five factors and facets and the prediction of behavior. Journal of Personality and Social Psychology, 81, 524-539

Peterson, C., \& Stunkard, A. J. (1989). Personal control and health promotion. Social Science \& Medicine, 28, 819-828.

Robinson, H. M., Sigman, M. R., \& Wilson, J. P. (1997). Duty-related stressors and PTSD symptoms in suburban police officers. Psychological Reports, 81, 835-845.

Salancik, G. R., \& Pfeffer, J. 1978. A social information processing approach to job attitudes and task design. Administrative Science Quarterly, 23, 224-253.

Schaubroeck, J., Riolli, L.T., Peng, A.C., \& Spain, E.S. (2011). Resilience to traumatic exposure among soldiers deployed in combat. Journal of Occupational Health Psychology, 16, 18-37.

Sharkansky, E. J., King, D. W., King, L. A., Wolfe, J., Erickson, D. J., \& Stokes, L. R. (2000). Coping with Gulf War combat stress: Mediating and moderating effects. Journal of Abnormal Psychology, 109, 188-197.

Skinner, E. A., Edge, K., Altman, J., \& Sherwood, H. (2003). Searching for the structure of coping: A review and critique of category systems for classifying ways of coping. Psychological Bulletin, 129, 216-269.

Spector, P. E. (2006). Method variance in organizational research: Truth or urban legend? Organizational Research Methods, 9 , 221-232.

Stein, A. L., Tran, G. Q., Lund, L. M., Haji, U., Dashevsky, B. A., \& Baker, D. G. (2005). Correlates for posttraumatic stress disorder in Gulf War veterans: a retrospective study of main and moderating effects. Journal of Anxiety Disorders, 19, 861-876.

Stone, A. A., Kennedy-Moore, E., \& Neale, J. M. (1995). Association between daily coping and end-of-day mood. Health Psychology, 14, 341-349.

Stone, A. A., Schwartz, J. E., Neale, J. M., Shiffman, S., Marco, C. A., Hickcox, M., .. Cruise, L. J. (1998). A comparison of coping assessed by ecological momentary assessment and retrospective recall. Journal of Personality and Social Psychology, 74, 1670-1680.

Suls, J., \& Fletcher, B. (1985). The relative efficacy of avoidant and nonavoidant coping strategies: A meta-analysis. Health Psychology, 4, 249-288.

Suls, J., \& Martin, R. (2005). The daily life of the garden-variety neurotic: Reactivity, stressor exposure, mood spillover, and maladaptive coping. Journal of Personality, 73, 1485-1510.

Suvak, M. K., Vogt, D. S., Savarese, V. W., King, L. A., \& King, D. W. (2002). Relationship of war-zone coping strategies to long-term general life adjustment among Vietnam veterans: Combat exposure as a moderator variable. Personality and Social Psychology Bulletin, 28, 974-985.

Tamres, L. K., Janicki, D., \& Helgeson, V. S. (2002). Sex differences in coping behavior: A meta-analytic review and an examination of relative coping. Personality and Social Psychology Review, 6, 2-30.

Taylor, S. E., \& Brown, J. D. (1988). Illusion and well-being: A social psychological perspective on mental health. Psychological Bulletin, 103, 193-210. 
Terry, D. J., \& Hynes, G. J. (1998). Adjustment to a low-control situation: Reexamining the role of coping responses. Journal of Personality and Social Psychology, 74, 1078-1092.

Todrank Heth, J., \& Somer, E. (2002). Characterizing stress tolerance: A new approach to controllability and its relationship to perceived stress and reported health. Personality and Individual Differences, 33, 883-895.

Tyler, P. A., \& Cushway, D. (1995). Stress in nurses: The effects of coping and social support. Stress Medicine 11, $243-251$.

Vollrath, M., \& Torgersen, S. (2000). Personality types and coping. Personality and Individual Differences, 29, $367-378$.

Wagner, D., Heinrichs, M., \& Ehlert, U. (1998). Prevalence of symptoms of posttraumatic stress disorder in German professional firefighters. American Journal of Psychiatry, 155, 1727-1732.

Watson, D., \& Clark, L. A. (1997). Extraversion and its positive emotional core. Handbook of Personality Psychology, 24, 767-793.

Wolfe, J., Keane, T. M., Kaloupek, D. G., Mora, C. A., \& Wine, P. (1993). Patterns of positive readjustment in Vietnam combat veterans. Journal of Traumatic Stress, 6, 179-193.

Zellars, K. L., \& Perrewé, P. L. (2001). Affective personality and the content of emotional social support: Coping in organizations. Journal of Applied Psychology, 86, 459-467. 